Bulwer-Lytton E. Pelham. Mode of access: http://www.gutenberg.org/files/7623/7623-h/7623-h.htm

Bul'ver-Litton Pe`lem, ili priklyucheniya dzhentl`mena. [Bulwer-Lytton Pelham, the adventuries of a gentleman ], M.Xudozhestvennaya literatura,- 1958-S. XVhttps://www.litmir.me/br/?b=129463\&p=1

For citation:

Bezkorovaynaya Galina (2019) DENOTATIVE AND TRANSFORMATIONAL APPROACHES TO THE TRANSLATION OF IDIOMS FROM ENGLISH INTO RUSSIAN // International Scientific-Pedagogical Organization of Philologists " WEST-EAST " (ISPOP). Scientific Journal WEST-EAST. Vol 2/1 N1 (October, 2019). pp. 162-165. doi:

Для цитирования:

Безкоровайная Г. Т (2019) ДЕНОТАТИВНЫЙ И ТРАНСФОРМАЦИОННЫЙ ПОДХОДЫ К ПЕРЕВОДУ ФРАЗЕОЛОГИЗМОВ С АНГЛИЙСКОГО ЯЗЫКА НА РУССКИЙ // Internationa 1Scientific-Pedagogical Organization of Philologists “WEST-EAST” (ISPOP) . Scientific Journal WEST-EAST. Vol 1/1 N1 (October, 2019). C. 162-165. doi:

Information about the author: Bezkorovaynaya Galina - Candidate of Philology, Assistant Professor, department of foreign languages Moscow Polytechnic University, High School of Printing and Media Industry

e-mail: begati1@yandex.ru

Информация об авторе: Безкоровайная Галина Тиграновна - кандидат филол. наук, доцент кафедры « Иностранные языки», Московский политехнический университет, Высшая школа печати и медиаиндустрии.

e-mail: begati1@yandex.ru

Manuscript received: 05/27/2019 Accepted for publication: 09/20/2019

DOI:

\title{
LINGUOCULTUROLOGICAL TRANSLATION PECULIARITIES OF DIPLOMATIC CORRESPONDANCE OF FRENCH CONSULATES IN GEORGIA AND TURKEY (middle $19^{\text {th }}$-early20 ${ }^{\text {th }}$ )
}

\author{
Victoria Diasamidze \\ Doctor of Philology, Associate professor \\ Batumi Shota Rustaveli State University \\ (Batumi, Georgia) \\ e-mail: victoria.diasamidze 777
}

\begin{abstract}
The paper deals with the theoretical understanding and linguocultural interpretation from French into Russian of the archival diplomatic correspondence of the consulates of France in Georgia and the Ministries of Foreign Affairs of France and Turkey of the late XIXth-early XXth century. In this paper we analyse lexical, phraseological features and compare standard architectonics of drawing up official and business handwritten correspondence. Compliance with ethical and professional rules and regulations dictates the specific features of the syntax and appeal to the higher and lower officials. When translating into Russian, idioms and equivalents, generally accepted in official business correspondence with maximum preservation of color and features peculiar to the original, were taken into account.
\end{abstract}

Key words: diplomatic correspondence, French diplomacy, correspondence rules, handwritten discourse

\section{ЛИНГВОКУЛЬТУРОЛОГИЧЕСКИЕ ОСОБЕННОСТИ ПЕРЕВОДА ДИПЛОМАТИЧЕСКОЙ ПЕРЕПИСКИ КОНСУЛЬСТВ ФРАНЦИИ В ГРУЗИИ И ТУРЦИИ (сер. ХІХ-нач. ХХ века)}

\author{
Виктория Григорьевна Диасамидзе \\ Кандидат филологических наук, ассоциированный профессор \\ Батумский государственный университет \\ имени Шота Руставели \\ (Батуми, Грузия) \\ e-mail: victoria.diasamidze777@mail.ru
}

\begin{abstract}
Аннотация. Представленная работа посвящена лингвокультурологической интерпретации перевода с французского языка на русский архивной дипломатической переписки консульств Франции в Грузии МИД Франции и Турции конца XIX-начала $\mathrm{XX}$ века. Рассматриваются лексические, фразеологические и другие особенности, сравнивается принятая архитектоника составления официально-деловой переписки, по понятным причинам почти исключительно рукописного характера. Соблюдение этических и профессиональных правил и норм диктует специфические особенности синтаксиса и обращения к высшему и низшему должностному составу. При переводе на русский язык, прежде всего, учитывались идиомы и эквиваленты, общепринятые в официально-деловой переписке при максимальной сохранности колорита и особенностей, свойственных оригиналу.
\end{abstract}


Ключевые слова: дипломатическая переписка, французская дипломатия, правила переписки, дискурс рукописной корреспонденции

ВВЕДЕНИЕ. Начиная с XVIII века, доминирующим в дипломатии был французский язык; французскую дипломатию формировала большая плеяда выдающихся личностей и документы изначально отличались особым изяществом. В настоящей работе нами предпринята попытка сделать обобщенный анализ и дать характеристику особенностей дипломатической переписки на французском языке, выявить общие и различные черты её ведения в дипломатических отношениях Франции и Турции с консульской службой Батуми за период с середины XIX до начала XX века.

Фактическим материалом исследованию послужили тексты на французском языке из официальных архивов МИД Франции и Турции по различным внешнеполитическим вопросам и текущим вопросам международного сотрудничества, предоставленные г-ном Зауром Маргиевым,д окторантом Тбилисского государственного университета им. И. Джавахишвили.

МЕТОДЫ ИССЛЕДОВАНИЯ. Основным методом исследования является культурологический и сопоставительно-типологический анализ, который позволяет выявить лексико-семантические единицы исходного языка и языка перевода.

ОБЗОР ЛИТЕРАТУРЫ. Каждый вид дипломатической документации используется для решения определенных задач. Дипломатическая переписка является одной из форм делопроизводства в области международных отношений и переписки. Формальные правила переписки, внешняя атрибутика корреспонденции сложились полтора века назад. Специалистами по составлению дипломатических документов выделяются обычно следующие обязательные элементы: протокольные формулы, смысловое ядро, аргументация своей позиции.

В исследуемый период большая часть работы дипломатов заключалась в написании депеш, составляющих, наряду с шифрованными телеграммами, основной способ обмена информацией сотрудников консульских служб.

Французская дипломатическая служба, как отметил известный дипломат Ю.В.Дубинин, Командор французского национального ордена «За заслуги», всегда была самой большой по сравнению со службами других иностранных государств. Являясь одной из основоположников современной мировой дипломатии, французская дипломатия входит в первую тройку, наряду с английской и восточной (Dubinin 2004:38-69).

В последнее время оживилась дискуссия о роли и месте дипломатии по сравнению с прошлыми эпохами: теоретический и практический интерес представляет рассмотрение не только современных процессов в дипломатической службе Франции (Litvak 2016:18).

Как и в прежние времена, источниками качественной информации остаются контакты с людьми и набор собеседников, общение с которыми дает хорошую картину для досье дипломата. Тематика переводимой переписки различна: собирался и изучался материал о текущей ситуации за рубежом, делались прогнозы развития событий и предложения для достижения целей, поставленных политическим руководством.

РЕЗУЛЬТАТЫ И ДИСКУССИЯ. Нельзя не отметить высокую степень грамотности, общей культуры и профессионализма составителей и авторов переводимой нами и введенной в научный обиход документации. При переводе документации консульских и министерских служб мы столкнулись с неизбежными проблемами, связанными с неразборчивостью почерка, перепиской пером и чернилами в эпоху, предшествующую появлению печатной машинки. Это объясняет орфографические и стилистические погрешности в рукописном материале. Мы обратим внимание лишь на некоторые из них, часто повторяющиеся или не соответствующие высокому статусу писавшего. В массиве объёмом около двух тысяч архивных рукописных листов исключительно редки ошибки, носящие, скорее, механический характер. Стилистические правки карандашом нередки на переводимых нами документах и носят, как правило, либо уточняющий, либо смягчающий жесткость позиции характер. К таким отклонениям по отношению к общепринятой орфографии можно отнести встреченное написание топонимов и даже имен собственных со строчной буквы. Так, остаётся лишь догадываться, отчего консул Франции в Кавказских провинциях, г-н Стайерт, неизменно подписывается "fr. Steyert" в своих письмах из Батума Министру иностранных дел, вместо общепринятого "Fr.Steyert”. Непоследовательность в обозначении топонимов проявляется в "mernoire”, “hopa”, “anapa”,"batoum”, a то и "batoun”. Изящество стиля и соблюдение, как правило, норм орфографии не позволяют ставить под сомнение высокую степень грамотности потомственного аристократа Фр.Стайерта. Это же касается довольно распространенного в нашем фактическом материале отступления от норм орфографии в окончаниях наречий и имен существительных на -ment, -ant, -em. Необычно читать спустя 150 лет у разных авторов“"tems”/temps, “enfans"/enfant,"sentimens"/sentiments. Согласно нормативным грамматикам и пособиям по истории французского языка, орфографические нормы утвердились ещё в 12 столетии, и в особенностях орфографии 19 века подобные отступления не фигурируют (Katagoshchina atc.1976:269-270; Shigarevskaya 1974:235-236).

Фактический же материал показывает обратное: установление норм орфографии в живом языке развивающийся процесс.

Говоря об особенностях обозначения топонимики эпохи времён турецкого владычества, невозможно не упомянуть постфикс “-Кalé”при наименовании городов во времена турецкого владычества, названия рек утратили свою вторую составную часть «цхали», заменив её на «су»/sou (Маргиев,2008:418): Kemhel/Pedym- 
Кале, Сухум-Кале/Soukhoum-Kalé, Чурук-су/Tchourouk-sou, Аджара-cy/Adjara-sou, например: «В Редут-Кале господин Шампуазо, не найдя себе пристанища, был направлен в лагерь на Чурук-су, где оставался несколько дней в лихорадке и без оказания помощи».

Ориентализмы являются непременной составной консульской переписки со странами Востока; начнём с упоминания градации гражданских лиц в зависимости от места, занимаемого лицами в обществе: почетный титул гражданских и военных чинов «-ага», титул правителей различных рангов «-бей», высший государственный сановник -«визирь»,паша 1-го класса- «мушир», указ, издававшийся от имени султана и скрепленный его тугрой (знак в виде монограммы) -«ферман»и др.(там же:697-744):«Поскольку лодка не смогла пристать к берегу Чурук-су из-за сильного ветра, они решили продолжсть свой путь и вошли в порт Батума, где капитан Солиман-ага передал господина Мариополи в руки генерала Этэм-паши/Еthетрасһа»; «Счтаю своим долгом сообщить его Превосходительству Великому Визирю (что я сделаю это также в посольстве Константинополя и МИД Парижа) об испытываемых нами трудностях в получении результата в кратчайшие сроки...»;«Вчера, 23 декабря, 1854 года, мушир, главнокомандуюший армейским корпусом БатумаМустафа-паша, публично огласил Ферман Султана относительно запрета на торговлю черкесскими и грузинскими рабами» (Попутно отметим, что в Османской империи институт рабства продержался дольше, чем в других регионах мира и только в 1876 году султанским указом на территории империи рабство официально было запрещено).

Немалую роль в работе консульств играли так называемые толмачи - драгоманы, от добросовестности которых зачастую зависел исход многих дел. Драгоман (франц. Dragoman из араб.) - официальная должность переводчика и посредника между ближневосточными и азиатскими державами и европейскими дипломатическими и торговыми представительствами. Должность предполагала как переводческие, так и дипломатические функции. Драгоман обычно владел османским или арабским и, как минимум, одним из европейских языков. Драгоманы работали в рамках администрации Османской империи, а также в составе европейских дипломатических, торговых представительств ,согласно «Словарю руского языка»(Словарь русского языка:1999). В консульской переписке часто мелькают весьма нелестные характеристики упомянутых драгоманов:«...факт, заслуживающий большого сожаления, состочт в том, что настолько важное дело с материальной точки зрения для компании Махсуссе/Mahsoussé и для правительства османской империи (ибо дело о земельном участке ценой не менее, чем 15.000 руб.),находится в руках такой личности, как драгоманКости Шумул-оглу/CostiSchouтоulOglou, виновный в преступной смене подданства без особого на то позволения Его Величества, Светлейшего и Всемогущественного Правителя, не говоря уже о прочих злоупотреблениях вышеназванного субъекта».И ещё один пример недостаточной преданности службе одного из драгоманов: "Мой отъезд из Трапезунда несколько задержался из-за увольнения некоего Шахума/Shahит, бывшего год у меня на службе в Тифлисе. Там мне поручили защищать османских подданных, что, впрочем, произошло в прошлом августе. В действительности, ситуация была обусловлена малой преданностью делу, отстаиваемому в настоящий момент. Как следствие, это вызвало увольнение этого драгомана и обязало меня найти ему замену в Константинополе».

Один из часто употребляемых ориентализмов - башибузук (от тюркского «баш» -голова и «бузук» испорченный, бешеный) имеет следующие значения: 1) ист. солдат нерегулярной конницы в Турции в 18-19 вв.; 2) в переносном смысле - «грубый, необузданный человек; разбойник, головорез (Маргиев, 2008:701): «Согласно сообщению мушира, ...nроизошло нападение на укрепленный лагерь Лагва/ Laghva в двух лье от Чурук-су. Этот аванпост, состоящий из 800 человек башибузуков/Bachi-Bоитоикs Верхней Аджарии, вчера утром был атакован грузинскими войсками, численность которых, около пяти тысяч человек».

Летоисчисление, принятое в Османской империи, использовалось и в международной переписке, например, при обращении к Консулу Франции в Кавказских провинциях, мушир, главнокомандующий армейским корпусом Батума, Мустафа-пашаиз Штаб-квартиры в Чурук-су, 12 джемаз-эвел 1271г./12 djemaz-elevrel 1271,пишет следующее13 февраля 1855 года:«Господин Консул, я получил Вашу депешу от 8 джемаз-элэвела, в которой Bbl просите информировать Вас о принятых мерах по освобождению семи человек, похищенных людьми из Верхней Аджарии».

Дипломаты исследуемого периода активно использовали термины из латыни. В нашем материалевстречено значительное количество подобных примеров: «Его Превосходительство Рустем Паша Его Превосходительству Саид Паше, министру иностранных дел. Константинополь, 11 августа 1886 года. ... «Лорд Солсбери ... ответил мне, что уже сейчас, арriori, ему не кажется выгодным продолжать «чернильную войну» с полемикой, не способной привести к какому-либо решению».Используемый здесь же фразеологизм метафорического характера чернильная война/guerre de l'encre, иронически означает «письменный, выражающийся только в переписке, выступлениях в печати», вошёл в разряд архаизмов с середины прошлого века в связи с исчезнувшими из обихода реалиями. Латинизм Clausularebussicstantibus широко используется при дискуссии вокруг отмены статьи Берлинского договора, дающей Батуми статус порто-франко: «...cогласно "Clausularebussicstantibus», право одностороннего расторжения, действительно, признаётся за государством в отношении заключенного им договора, если преобладавшие условия во время заключения данного договора со временем значительно изменились». 
При проставлении даты в дипломатической переписке в конце 19 века используется архаичное обозначение месяцев, соответствующее их латинской этимологии. Это объясняется тем, что французский язык в официально-деловой переписке пришёл на смену латыни относительно недавно: так, сентябрь, дословно, седьмой месяц-“sерtет”, обозначается в виде “"7-e”(septembre), ноябрь, девятый месяц-“поует”, обозначается в виде “ 9 e”(nоvетbre), декабрь, десятый месяи-“dесет”, обозначается в виде “ $\boldsymbol{X}$ bre"(décembre) и и.д.

Формулы вежливости, правила написания дипломатической документации, ведение переписки уже имели стандартный устойчивый характер, используемый во всем мире. Уход от клише и международных стандартов нами не был отмечен и не приветствовался в дипломатической переписке. Традиционно не требовалось комплиментарного оформления только в таких документах дипломатической переписки, как памятные записки и меморандумы.

Обращение традиционно включает в себя указание официального поста или принятого титула (Господин Министр», «Ваше Превосходительство» и др.). В нашей документации встречаются оба варианта. Располагается обращение немного отступив вниз от адреса получателя и начинается, как правило, на той же вертикали, что и текст письма. После обращения при написании на французском языке принято ставить запятую или двоеточие. В исследуемый период нам встретился только первый вариант; текст самого письма всегда начинается с красной строки и с заглавной буквы, несмотря на то, что следует после запятой или двоеточия:ґ Господин Министр, В своём последнем письме за № 21, я имел честь сообщить Вашему Превосходительству о том, что войско в Армении постепенно сократилось по причине болезней и отозвания 8 Россию дивизии гранатомётчиков и других войск, не относящихся к Кавказу.Эта новость подтверждается многими офицерами, покинувшими Тифлис, чтобы примкнуть к своим основным корпусам. В одном полку лишь у четырёх офицеров не было тифа. В общей сложности только одна пятая часть его избежала, а остальные ближайшие полгода не в состоянии нести любую службу. Тем не менее, отбытие из Поти было задержано, поскольку, как 12 мая пишет г-н де Ла Шом, на побережье сосредотачиваются войска и среди прочих остатки дивизии гранатомётчиков, по численности не более батальона. Генерал Комаров, находящийся ещё только в 15 верстах от Чороха, просит подкрепления, ...» и далее по тексту.

Даже если содержание дипломатической документации неприятно для адресанта, протокольная формула соблюдается без исключений. Так ,консул Кавказских провинций Стайерт,возлагая на губернатора и мушира, главнокомандующего Батумским корпусом армии, всю«ответственность за несльханное деяние, насильственное похищение у власти подданного дружественной и союзной державы, коммерсанта, который, как вам обоим хорошо известно, пользуется протекцией Франции», однако, заканчивает письмо традиционным:«Примите, господин Губернатор, уверения в моём глубоком почтении».

Интересная деталь: в переписке консульства Турции с консульством Франции в Батуме того периода фигурирует термин, обозначающий правительственноеучреждение в Константинополеи содержащий элемент самовосхваления.В начале 80-х годов 19 века вместо Министерства иностранных дел употреблялосьсловосочетаниеSublimePorte,буквально означающее «Величественные ворота» во дворец Главного Визиря Султана, а затем МИД Османской империи. В общепринятом употреблении словосочетание SublimePorte переводится, как Блистательная Порта. Существует следующее определение и синонимичные выражения: По́рта,также Оттоманская Порта, Блистательная Порта, Высокая Порта - принятое в истории дипломатии и международных отношений наименование правительства, конкретнее - канцелярии Великого Визиря и дивана Османской империи. Сам термин происходит от французского porte, итальянского porta - «дверь», «врата», что является калькой с османского Bâb-ı Âli - «высокие ворота».

В дипломатическом дискурсе корректно подготовленное письмо в структурном отношении выглядит, как правило, следующим образом: дата, включающая число, месяц и год написания (как правило, в сокращенном виде не воспроизводится), ставится под адресом отправителя. Адрес получателя помещается ниже адреса отправителя только в левом верхнем углу письма. Однако в исследуемый период времени почта доставлялась исключительно курьерами из соображений строгой секретности, поэтому полный адрес, как правило, не указывался. Возможно, этим объясняется то, что дипломатический дискурс исследуемого периода начинается с непосредственного обращения адресанта, в данном случае, вице-консула Франции в Батуме Оливье де Шаппделена (OlivierdeChappedelaine) к адресату, министру иностранных дел.Только в конце первой страницы проставляется полный титул адресата:«Его Превосходительству Министру Иностранных дел от Вице-Консула Франции в Батуми Оливье де Шаппделена /OlivierdeChappedelaine из Тифлиса, 17 мая 1878года».

Комплимент как заключительная формула вежливости, завершающая письмо, выбирается с учетом адресата и характера переписки. Например: «Примите, господин Министр (воспроизводится чаще всего титул, содержащийся в обращении), уверения в моем весьма высоком уважении» и др. Их вариативность в рассматриваемый период незначительна. В основном это рамочное оформление сводится к следующим формулам: «Имею честь, господин Министр, быть преданнейшим слугой Вашего Превосходительства»/J'ail'honneurd'être, Monsieur le Ministre, de Votre Excellence letrès dévoué serviteur” (1882 год). Ср.: (1879 год) “'Agréez l'hommage du respect avec lequel j'ai l'honneur d'être, Monsieur le Ministre, de Votre Excellence le très humble et très obéissant serviteur”/«Примите заверения в моем почтении, Ваше Превосходительство, господин Министр, Ваш покорнейший и преданнейший слуга».При этом упоминание 
«покорнейшего ипослушнейшего слуги»- адресанта постепенно, с приходом Нового времени, стало примером устаревшего употребления.При всей витиеватости клятв в верноподданничестве, содержащихся в формулах вежливости, характерной особенностью периода всё же была самостоятельность дипломатов, так как действовали они вдали от центра и вся связь ограничивалась почтовыми отправлениями (Пановһttps://russiancouncil.ru/.../zarubezhnaya-diplomaticheskaya-sluzhba-rossii-vtoroy-ch..). Отметим,что крайней неразборчивостью почерка и сокращенными до минимума комплиментами, завершающими письмо (Примите $u$ np./Recevez, etc.), чаще всего грешат высокопоставленные лица на вершине иерархической лестницы, дополнительные трудности создаёт крайне неразборчивый почерк министров иностранных дел: таков примерный перевод фактически неразборчивого текста министра иностранных дел, госсекретаря департамента: «Господину Кавалеру Гамба/ Le Chevalier Gamba. Париж, апрель 1830 года. Господин, Ваша депеша от 1 января сего года подтвердила подробность, уже полученную послом (неразборчиво) 6 Константинополе относительно убийства, жертвой которого пал господин Доктор Шульз на границе Курдистана (неразборчиво).(неразборчиво) узнали с болью об этом событии, лишившего нас человека, на которого Правительство возлагало большие надежды. Благодарим за проявленный интерес и участие в этом деле полковника Макдональда и всех тех, кто принял живое участие в печальной участи этого путешественника. Мы узнали с удовлетворением о выполнении обещания, данного полковником Макдональдом разобраться в этом убийстве. Благодарим также за адресованнье господину графу Гильемино/Guilleminot список вещеей и бумаг, принадлежавиих Доктору Шульзу. Примите и т.д.».

Дипломатическая телеграмма (ДТ), ранее называемая телеграфной депешей,обычно не сопровождается адресами и указанием отправителя с адресатом. В ней отсутствуют обращения и финальная формула вежливости. Подпись фамилией адресанта завершается ДТ, ставшая постепенно основной, наряду с депешами, формой дипломатической переписки: «Тифлис, 29 июля 1878 года, 10 августа по новому стилю.Вчера сюда прибыл турецкий полковник для организаччи оккупачии Батума. Утверждают, что оккупачия 38-й и 39-й дивизиями будет завершена спустя неделю.Шаппделен».

Если после написания письма возникла неотложная необходимость сообщить о событиях, которые произошли позже, то после заглавных латинских P.S. (Postscriptum) дописывалась необходимая информация. Постскриптум, как правило, не подписывался; в конце его автор ставил свои инициалы. Злоупотреблять этой формой в деловой переписке не принято. Поэтому примеры составляют редчайшие случаи и, как правило, касаются событий, непосредственно последовавших составлению письма, как, например, в случае констатации вспышек малярии, обычных для Батума вплоть до 30-х годов прошлого века:«P.S. B момент закрытия депеши ко мне вошел господин Шампуазо и своим рассказом, который я не успею Вам передать, господин Поверенный в делах, он подтвердил моё предположение, что он стал жертвой злой воли со стороны Мустафы-паши».

Ещё одной особенностью документов, оформляемых секретарями под диктовку, являются общепринятые сокращения титулов и званий, к примеру: "S.E. - SonExcellence/Bame Превосходительство, S.M. - Sa Magesté/Ваше Величество, S.A.I. - Son Altesse Impériale/Bame Императорское Высочество“ и т.д. Аббревиатуры встречаются и среди объёмных топонимов; так, «длинное» “Constantinople” усекается до "Cons/ple".

Заимствований, кроме вынужденных ориентализмов, в наших текстах не наблюдается; даже те два, пришедшие из английского языка, «steamer»/napoxod $u$ «tonne»/mонна, сменившая русский пуд, встретились в сугубо портовой тематике Батума.При всей открытости лексической системы по сравнению с грамматической нами зафиксированы отдельные обозначения реалий административно управленческого аппарата.

ЗАКЛЮЧЕНИЕ. Таким образом, французская дипломатическая служба исследуемого периода традиционно следовала правилам и нормам общепринятой международной дипломатической переписки. Её специфика лексического и орфографического свойства обусловлена как отдаленностью эпохи, так и её культурноисторическим фоном.

\section{LIST OF REFERENCES}

Dubinin,Y.V.,(2004). DiplomatitcheskayaslujbaFrantsii.[French Diplomatic Service]. / Dubinin Y.V. // State Diplomacy of the Foreign States: utcheb. posobie / pod red.T.V.Zonovoi; MGIMO (U)MID RF,Moskva: ROSSPEN, 38-69.

Katagoshchina N.A.,idrugiye.(1976).Istoriyafrantsuzskogoyazyka. Moskva, Vysshayashkola: 1976/Katagoshchina N.A. other. History of the French language.Moscow, HigherSchool: 1976.

Litvak,N.V.,(2016). Informatsionnieprotsessi v sovremennoi diplomatitcheskoi slujbe.OpitFrantsii. [Information Processes in Modern Diplomatic Service. French Experience].Moskva: Izdatelstvo MGIMO.

Marguiev Z.(2008). Batum vovremenaosmanskoyimperii.[Batum during the Ottoman Empire]Batumi:IzdatelstvoAlioni.

Panov A.N.(2015). ZarubejnaiyadiplomatitcheskaiyaslujbaRossiivtoroitchetverti XIX...[ Foreign diplomatic service of Russia in the $19^{\text {th }}$ century].https://russiancouncil.ru/.../zarubezhnaya-diplomaticheskaya-sluzhba-rossii-vtoroy-ch..

Shigarevskaya N. A.,(1974).Istoriya frantsuzskogo yazyka. Leningrad:1974/Shigarevskaya N.A. History of the French language. Leningrad: Enlightenment. 


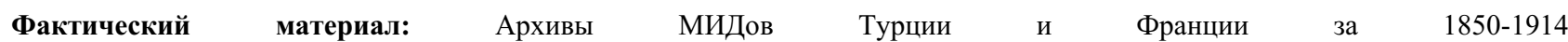
гг.HR_HMŞ_İŞO_00065_00012_001_001HR_SYS_01950_00062_001_001;HR_SYS_01950_00062_001_001;DSC _ 8916DSC_9008(Предъявление по первому требованию).

For citation:

Diasamidze Victoria (2019) LINGUOCULTUROLOGICAL TRANSLATION PECULIARITIES OF DIPLOMATIC CORRESPONDANCE OF FRENCH CONSULATES IN GEORGIA AND TURKEY (middle $19^{\text {th }}$-early $20^{\text {th }}$ ) // International Scientific-Pedagogical Organization of Philologists “WEST-EAST” (ISPOP). Scientific Journal WEST-EAST. Vol 2/1 N1 (October, 2019). p.165-170. doi:

Для цитирования:

Диасамидзе В. Г. (2019) ЛИНГВОКУЛЬТУРОЛОГИЧЕСКИЕ ОСОБЕННОСТИ ПЕРЕВОДА ДИПЛОМАТИЧЕСКОЙ ПЕРЕПИСКИ КОНСУЛЬСТВ ФРАНЦИИ В ГРУЗИИ И ТУРЦИИ (cep.ХІХ-нач.ХХ века) // Internationa 1ScientificPedagogical Organization of Philologists “WEST-EAST” (ISPOP) . Scientific Journal WEST-EAST. Vol 1/1 N1 (October, 2019). C. 164-169. doi:

Information about the author: Diasamidze Victoria- Doctor of Philological Sciences, associate professor, Batumi Shota Rustaveli State University,

(Batumi, Georgia)

e-mail: victoria.diasamidze777@mail.ru

Сведения об авторе: Диасамидзе Виктория Григорьевна-кандидат филологических наук, ассоциированный профессор, Батумский государственный университет имени Шота Руставели, Батуми, Грузия

e-mail: victoria.diasamidze777@mail.ru 